\title{
Klebsiella pneumoniae İzolatlarında Sıvı Mikrodilüsyon Temelli íki Ticari Sistemin Referans Mikrodilüsyon Yöntemine Göre Değerlendirilmesi
}

\author{
Evaluation of the Two Commercial Methods Based on Broth \\ Microdilution Against Reference Microdilution Method for \\ Klebsiella pneumoniae Isolates
}

\author{
Nilgün $\operatorname{KANSAK}^{1}\left(\right.$ ID), Müge $\operatorname{ASLAN}^{1}\left(\right.$ ID), Rıza ADALETi(ID), Sebahat AKSARAY ${ }^{1,2}($ ID) \\ 1 T.C. Sağlık Bakanlığı, İstanbul Haydarpaşa Numune Eğitim ve Araştırma Hastanesi Tıbbi Mikrobiyoloji Laboratuvarı, \\ istanbul. \\ 1 TR Ministry of Health, Istanbul Haydarpaşa Numune Education and Research Hospital, Medical Microbiology Laboratory, \\ istanbul, Turkey. \\ ${ }^{2}$ Sağlık Bilimleri Üniversitesi Hamidiye Tıp Fakültesi, Tıbbi Mikrobiyoloji Anabilim Dalı, İstanbul. \\ 2 Health Sciences University Hamidiye Faculty of Medicine, Department of Medical Microbiology, istanbul, Turkey.
}

* Bu çalışma, 5. Ulusal Klinik Mikrobiyoloji Kongresi (28 Ekim-1 Kasım 2019, Izmir)'nde sunulmuştur.

Makale Atıfı: Kansak N, Aslan M, Adaleti R, Aksaray S. Klebsiella pneumoniae izolatlarında sIVı mikrodilüsyon temelli iki ticari sistemin referans mikrodilüsyon yöntemine göre değerlendirilmesi. Mikrobiyol Bul 2020;54(4):606-612.

\section{Öz}

Çok ilaca dirençli gram-negatif bakteri enfeksiyonlarındaki artış ve artan kolistin direnci nedeni ile kolistin duyarılıı̆ının hızlı ve güvenilir bir yöntemle saptanması önemlidir. "Clinical and Laboratory Standards Institute (CLSI)" ve "European Committee on Antimicrobial Susceptibility Testing (EUCAST)" tarafından referans yöntem olarak sıvı mikrodilüsyon (SMD) yöntemi önerilmesine rağmen uygulama zorluğu ve zaman alıcı olması nedeni ile rutinde kullanımı sınırlıdır. SMD temelli, pratik uygulaması kolay birçok ticari ürün kullanıma girmiştir. Bu çalışmada, kolistin duyarıı̆ı̆ıın saptanmasında kullanımda olan iki ticari sistemin sonuçlarının referans yöntemle karşılaştııılması amaçlanmıştı. Çalışmaya, 2017-2018 döneminde çeşitli klinik örneklerden elde edilen 38 Klebsiella pneumoniae izolatı dahil edilmiştir. Bakteri tanımlama ve antibiyotik duyarlılık testleri "matrix-assisted laser desorption/ionization time-of-flight, mass spectrometry (MALDI-TOF MS)" ve Vitek-2 (bioMérieux, Fransa) sistemleri ile yapılmıştır. SMD testleri, Sensititre (Sensititre custom plate, Thermo Fisher Scientific, Birleşik Krallık) ve "Micronaut MIC-Strip" (Merlin Diagnostika $\mathrm{GmbH}$, Almanya) kitleri ile çalışılmıştır. Ticari SMD testleri, firma önerileri doğrultusunda 0.5 McFarland bakteri süspansiyonu kullanılarak 0.0625-128 mg/L konsantrasyon aralığında dehidrate kolistin içeren kitler ile yapılmıştır. Referans SMD testi, "International Organization for Standardization (ISO-20776-1)" önerileri doğrultusunda çalışılmışır. Kalite kontrolü, kolistin duyarı ATCC 25922 Escherichia coli ve kolistin dirençli NCTC 13846 ( $m$ cr-1 pozitif) E.coli suşları ile gerçekleştirilmiştir. EUCAST versiyon 9.0 önerileri doğrultusunda minimum inhibitör konsantrasyon değeri $\leq 2 \mathrm{mg} / \mathrm{L}$ olan izolatlar duyarlı, > 2 mg/L olan izolatlar dirençli olarak değerlendirilmiştir. Referans yöntemle izolatların 35'i kolistin dirençli, üçü duyarlı bulunmuştur. Sensititre kiti ile bir izolatta çok büyük hata saptanırken (\%2.8); 
Micronaut kiti ile büyük ve çok büyük hata saptanmamıştı. Sensititre ve Micronaut kitleri ile referans yöntemin temel ve kategorik uyumu, sırasıyla \%74-76 ve \%97-100 olarak belirlenmiştir. Çok ilaca dirençli bakterilerin neden olduğu ciddi enfeksiyonların tedavisi amacıyla son seçenek olarak kullanılan kolistin için çok büyük hata ve büyük hata eşit ciddiyette kabul edilmektedir. Sensititre kiti ile bir izolatta çok büyük hata saptanmasına rağmen referans yöntemle kıyaslandığında, her iki ticari kitin kategorik uyumu > \%90 bulunmuştur. Sonuç olarak, ek ekipman ve tecrübe gerektirmeyen SMD temelli ticari sistemlerin rutinde kullanılabileceği gösterilmiştir.

Anahtar kelimeler: Kolistin; antibiyotik duyarlıık testi; ilaç direnci; sIvı mikrodilüsyon; minimum inhibitör konsantrasyon.

\section{ABSTRACT}

A rapid and reliable method for antimicrobial susceptibility test of colistin is needed because of increasing numbers of multi-resistant gram negative bacterial infections and simultaneus increasing of colistin resistance. Although broth microdilution (BMD) is recommended by the Clinical and Laboratory Standards Institute (CLSI) and the European Committee for Antimicrobial Susceptibility Testing (EUCAST) as a reference method, the use in routine laboratory practice is limited because of the difficulties in application and time-consuming characteristics. Recently, many BMD based commercial products were developed. The study was aimed to compare the results of the two commercial systems available for the detection of colistin sensitivity with the reference method. Totally 38 Klebsiella pneumoniae strains isolated from various clinical specimens between 2017-2018 were included in our study. Identification and antibiotic susceptibility tests were performed with "matrix-assisted laser desorption/ionization timeof-flight, mass spectrometry (MALDI-TOF MS)" and Vitek-2 (bioMérieux, Marcyl'Etoile, France) systems. BMD tests were performed with Sensititre (Sensititre custom plate, Thermo Fisher Scientific, UK) and Micronaut MIC-Strip (Merlin Diagnostika GmbH, Germany) kits. Commercial BMD assays containing dehydrated colistin in the concentration range of $0.0625-128 \mathrm{mg} / \mathrm{L}$ were tested with $0.5 \mathrm{McF}$ (arland bacterial suspensions prepared according to the manufacturer recommendations. The reference BMD test was performed by following the recommendations of the International Organization for Standardization (ISO-20776-1). ATCC 25922 colistin-susceptible Escherichia coli and NCTC 13846 (mcr-1 positive) colistin-resistant E.coli strains were used as the quality control strains. According to the recommendations of EUCAST version 9.0, strains with minimum inhibitory concentration value of $\leq 2 \mathrm{mg} / \mathrm{L}$ were considered susceptible and strains $>2 \mathrm{mg} / \mathrm{L}$ as resistant. Thirty-five isolates were resistant to colistin by the reference method and three of them were susceptible. The Sensititre kit detected a very major error $(2.8 \%)$ in one isolate; no major or very major errors were detected for the Micronaut kit. The essential and categorical agreement of the Sensititre and Micronaut kits with the reference method was defined as $74-76 \%$ and $97-100 \%$, respectively. Colistin is the last agent for the treatment of the multi drug resistant severe bacterial infections so major and very major error for colistin should be considered equally serious. Although a very major error was detected by the Sensititre kit in one isolate, the categorical agreement of both commercial kits was greater than $90 \%$ when compared with the reference method. It was concluded that, commercially available, BMD based systems that do not require additional equipment and experience can be routinely used.

Keywords: Colistin; antibiotic susceptibility testing; drug resistance; broth microdilution; minimum inhibitor concentration.

\section{GíRiş}

Kolistin, Paenibacillus polymyxa organizmasından izole edilen polimiksin grubu antimikrobiyal ilaç grubuna ait bir antibiyotiktir. Bu gruptaki moleküller A'dan E'ye kadar ayrılmış olup, yalnızca polimiksin E (kolistin) ve polimiksin B insan enfeksiyonlarının tedavisi için klinik kullanımda bulunmaktadır. Kolistin, polimiksin E1 ve E2'nin karışımı- 
dır. Gram-negatif bakterilerin dış membranında yer alan lipopolisakkarit ve fosfolipitlere bağlanarak membran bozulması ve hücre ölümüne neden olmaktadır ${ }^{1}$. Çok ilaca dirençli mikroorganizmalarla oluşan bakteri enfeksiyonlarındaki tedavi seçeneklerinin kısıtlılığı, özellikle karbapenem dirençli bakteri enfeksiyonlarında son tedavi seçeneği olarak kolistinin önemini tekrar gündeme getirmiştir ${ }^{2}$. Polimiksin grubu antibiyotiklerin artan kullanımı, kazanılmış kolistin direnci artışına neden olmuştur. Kolistin direncinin en sık nedeni, lipit A sentezini düzenleyici sistemi kodlayan genlerdeki mutasyon sonucu dış membran negatifliğinin ve sonrasında kolistinin bağlanmasının azalmasıdır. illk olarak 2015 yılında plazmit aracılı kolistin direncinin ( $m c r-1)$ tanımlanmasını takiben diğer mcr varyantları (mcr-2/mcr-8) görülmeye başlamıştır. Plazmit aracılı direncin kolaylıkla yayılabilme potansiyeli dolayısıyla kolistin direnci; küresel bir sorun olarak algılanmış ve önemli bir halk sağlığı problemi olarak değerlendirilmiştir ${ }^{3}$.

Kolistin için antimikrobiyal duyarlılık testleri birçok nedenle teknik olarak sorun oluşturmaktadır. Bunun ana nedeni, büyük molekül ağırlığına sahip olan kolistinin agara difüzyonunun zor olması, bu durumun disk difüzyon ve gradiyent test yöntemlerinin performansını düşürmesidir ${ }^{1}$. Yapılan çalışmalarda, yarı-otomatize sistemlerin performanslarının da kolistin direncini saptamada yeterli olmadığı gösterilmiştir ${ }^{4,5}$. 2017 yılında "Clinical and Laboratory Standards Institute (CLSI)" ve "European Committee on Antimicrobial Susceptibility Testing (EUCAST)" ortak çalışma grubu, kolistin duyarlılığının belirlenmesinde polistren mikroplak ve kolistin sülfat tuzu kullanımını, referans yöntem olarak ise "International Organization for Standardization (ISO)" standart sIVı mikrodilüsyon yöntemine (SMD) (20776-1) göre çalışılmasını önermiştir ${ }^{6,7}$.

Referans yöntem olarak SMD önerilmesine rağmen uygulama zorluğu, zaman alıcı olması ve taze hazırlanmış antibiyotik süspansiyonu kullanımını gerektirmesi gibi nedenler yöntemin rutinde kullanımını sınırlamaktadır. Kolistin duyarlılığının hızlı ve güvenilir bir yöntemle saptanması önemlidir. Son zamanlarda SMD temelli, pratik uygulaması kolay birçok ticari ürün kullanıma girmiştir. Bu çalışmada, kolistin duyarıılığının saptanması amacıyla üretilmiş iki ticari sistemin sonuçlarının referans yöntemle karşılaştırılması amaçlanmıştır.

\section{GEREÇ ve YÖNTEM}

Bu çalışmaya, 2017-2018 yılları arasında çeşitli klinik örneklerden [idrar $(n=18)$, kan $(n=7)$, solunum yolu örneği $(n=7)$ ve diğer $(n=6)$ ] izole edilip $-80^{\circ} \mathrm{C}^{\prime}$ de stoklanan, farklı hastalara ait çok ilaca dirençli 38 Klebsiella pneumoniae izolatı dahil edildi. İzolatların tanımlama ve antibiyotik duyarlılı testleri "matrix-assisted laser desorption/ ionization time-of-flight, mass spectrometry (MALDI-TOF MS)" ve Vitek-2 (bioMérieux, Marcyl'Etoile, Fransa) sistemi ile yapıldı. Referans SMD testi, ISO-standart (20776-1) önerilerine göre polistren mikroplak ve kolistin sülfat tuzu (Sigma-Aldrich C4461, ABD) kullanılarak yapıldı. Minimum inhibitör konsantrasyon (MiK) EUCAST önerileri doğrultusunda 0.125-128 mg/L dilüsyon aralığında çalışıldı. Öncelikle $51.2 \mathrm{mg}$ kolistin tartılıp $10 \mathrm{ml}$ 
steril distile suda $\left(\mathrm{dH}_{2} \mathrm{O}\right)$ çözülerek, stok solüsyon 1:10 oranında seri sulandırım yapılarak 512 mg/L kolistin içeren antibiyotik çözeltisi hazırlandı. Firma önerileri doğrultusunda katyon ayarlı Mueller Hinton buyyon (CAMHB) (Becton-Dickinson, Fransa) hazırlanarak, uygun Mik aralığında seri sulandırım yapılan kolistin kuyucuklara eklendi. Koyun kanlı agara pasajlanmış taze kültürden bakteri kolonileri alınarak steril serum fizyolojik içerisinde 0.5 McFarland $\left(1.5-2 \times 10^{8} \mathrm{cfu} / \mathrm{ml}\right)$ süspansiyon hazırlandı. Bakteri süspansiyonu ( $1: 100$ sulandırılarak hazırlanan ve $10^{6} \mathrm{cfu} / \mathrm{ml}$ bakteri içeren) her kuyucuğa, son bakteri konsantrasyonu $5 \times 10^{5}$ cfu olacak şekilde $50 \mu$ l dağıtıldı.

Çalışmada, mikrodilüsyon temeline dayanan 0.0625-128 mg/L konsantrasyon aralığında dehidrate kolistin ve üreme kontrol kuyucuğu içeren mikroplaklar halinde kullanıma hazır olarak üretilmiş Sensititre (Sensititre custom plate, Thermo Fisher Scientific, Birleşik Krallık) ve Micronaut MIC-Strip (Merlin Diagnostika GmbH, Almanya) marka kitler kullanıldı. Firma önerileri doğrultusunda, Sensititre için taze kültürden steril $\mathrm{dH}_{2} \mathrm{O}$ içerisinde 0.5 McFarland bakteri süspansiyonu hazırlandı. Hazırlanan çözeltiden $10 \mu$ l alınarak $11 \mathrm{ml}$ CAMHB içeren tüpe eklendi. Buradan $50 \mu \mathrm{l}$ alınarak, 0.12-128 mg/L kolistin içeren hazır mikroplaklara inoküle edildi.

Micronaut MIC-Strip testi için önce \%0.9 NaCl kullanılarak taze bakteri kolonilerinden 0.5 McFarland bakteri süspansiyonu hazırlandı. Bu çözeltiden $50 \mu$ alınarak $11.5 \mathrm{ml}$ CAMHB içeren tüplere dağıtıldı. Homojenizasyon sonrası 0.0625-64 mg/L kolistin içeren mikroplaklara $100 \mu$ l ekim yapıldı.

Çalışmamız, aynı gün içinde aynı ekip tarafından gerçekleştirildi. Bütün SMD plakları $35-37^{\circ} \mathrm{C}^{\prime}$ de $18-24$ saat inkübe edildi. İnkübasyon sonrasında sonuçlar, birbirinden bağımsız çift göz kontrollü olarak değerlendirildi. Kalite kontrolü, kolistin duyarlı ATCC 25922 Escherichia coli ve kolistin dirençli NCTC 13846 (mcr-1 pozitif) E.coli suşları ile gerçekleştirildi. EUCAST versiyon 9.0 önerileri doğrultusunda MiK değeri $\leq 2 \mathrm{mg} / \mathrm{L}$ olan izolatlar duyarlı, > 2 mg/L olan izolatlar dirençli olarak değerlendirildi 6 . Her iki ticari sistemin referans yöntemle temel uyumu (TU) (MiK değeri \pm 1 dilüsyon içinde olan sonuçlar) ve kategorik uyumu (KU) [örtüşen $(S, R)$ kategorik sonuç sayısı]; büyük hata $(B H)$ (referans yöntemle duyarlı olup, yanlış dirençli saptanan sonuçlar) ve çok büyük hata $(\mathrm{C} B \mathrm{BH})$ (referans yöntemle dirençli olup, yanlış duyarlı saptanan sonuçlar) oranları hesaplandı. Sonuçlar, ISO kriterlerine göre değerlendirildi (TU ve $\mathrm{KU}>\% 90 ; \mathrm{BH}$ ve $\mathrm{ÇBH}<\% 3)^{7}$.

\section{BULGULAR}

İzolatların 35'i referans yöntemle kolistine dirençli, üçü duyarlı bulunmuştur. Kalite kontrol suşlarının MiK değeri negatif kontrol ATCC 25922 için $0.5 \mathrm{mg} / \mathrm{L}$, pozitif kontrol NCTC 13846 için MiK: 4 mg/L olarak saptanmıştır. Sensititre ve Micronaut kitleri ile referans yöntemin TU ve KU oranları sırasıyla \%74-76 ve \%97-100 olarak belirlenmiştir. Sensititre ile bir hastada ÇBH saptanırken (\%2.8); Micronaut ile $\mathrm{BH}$ ve ÇBH saptanmamıştır. Çalışmanın sonuçları Tablo I'de özetlenmiştir. 
Klebsiella pneumoniae İzolatlarında Sıvı Mikrodilüsyon Temelli İki Ticari Sistemin Referans Mikrodilüsyon Yöntemine Göre Değerlendirilmesi

\begin{tabular}{|lccccccccc}
\hline \multicolumn{7}{l}{ Tablo I. Referans SMD Yöntemi ve Iki Farklı Ticari Sistemin Kolistin MiK (mg/L) Sonuçları } \\
\hline \multicolumn{7}{|c|}{ Kolistin MiK değerine sahip izolat sayısı (mg/L) } \\
\hline Yöntem & $\mathbf{1 2 8}$ & $\mathbf{6 4}$ & $\mathbf{3 2}$ & $\mathbf{1 6}$ & $\mathbf{8}$ & $\mathbf{4}$ & $\mathbf{2}$ & $\mathbf{0 . 5}$ & $\mathbf{0 . 2 5}$ \\
\hline Sensititre & 2 & 1 & 9 & 10 & 12 & - & 1 & 2 & 1 \\
Referans SMD & - & - & 2 & 7 & 22 & 4 & - & 1 & 2 \\
Micronaut & - & 3 & 10 & 15 & 5 & 2 & - & - & 3 \\
\hline SMD: Sivı mikrodilüsyon, MiK: Minimum inhibitör konsantrasyon.
\end{tabular}

\section{TARTIŞMA}

Antibiyotik duyarlılığının saptanması için kullanılan disk difüzyon ve gradiyent difüzyon testlerinin performansı, kolistin molekülünün agara zayıf difüzyonu nedeni ile düşük olduğundan rutin çalışmalarda kullanılması önerilmemektedir. Polimiksinlerin plastik yüzeylere bağlanması (pipet ucu, titrasyon plağı vb.) kolistin duyarlılığının saptanmasını zorlaştıran diğer bir teknik nedendir ${ }^{1}$. CLSI/EUCAST tarafından önerilen referans SMD testi emek yoğun, pahalı ve tecrübe gerektiren bir yöntem olduğundan, yüksek hata oranlarına rağmen bazı laboratuvarlar tarafından disk ve gradiyent difüzyon testlerinin kullanımına devam edilmektedir ${ }^{8}$. Kolistin duyarlılığını saptamaya yönelik olarak kullanılan Polymyxin NP gibi hızlı testler yüksek duyarlılık ve özgüllükteki sonuçlarına rağmen glikoz metabolizması üzerinden sonuç verdiğinden non-fermenter bakteriler için kullanımı sınırıdır ${ }^{9,10}$. Mevcut sorunlar ve kolistin duyarlıığının hızlı, doğru ve tekrarlanabilirliği yüksek bir yöntemle çalışılarak optimum tedavinin mümkün olan en kısa sürede başlanması gerekliliği, uygulaması kolay, ek ekipman ve tecrübe gerektirmeyen kullanıma hazır ticari SMD temelli testlerin birçok laboratuvar tarafından giderek artan oranlarda kullanımına neden olmuştur ${ }^{11}$.

2015 yılında rutin kullanılan duyarlılık testleri ile dirençli bulunan 41 K.pneumoniae izolatının altı farklı yöntemle kolistin direncinin karşılaştırıldığı çalışmada, polysorbate 80 (P80) ilaveli SMD yöntemi ile izolatların P80 ilavesiz SMD (referans yöntem) yöntemine göre yüksek oranda duyarlı saptandığı (\%12.2 ÇBH) bulunmuştur ${ }^{12}$. Bu nedenle ISOstandart SMD (20776-1)'de, artık SMD testlerinde herhangi bir katkı maddesi kullanılması önerilmemektedir ${ }^{13}$.

Pfennigwerth ve arkadaşları tarafından yapılan 206 K.pneumoniae izolatında altı farklı yöntemle kolistin direncinin kıyaslandığı çalışmada ${ }^{14}$, Micronaut-S ve Sensititre kitleri için TU ve KU oranları sırasıyla \%82.8-91.3 ve \%94.2-98.5 olarak bulunurken, Micronaut-S kiti ile bir izolatta $\mathrm{BH}$, iki izolatta $\mathrm{ÇBH}$; Sensititre kiti ile 10 izolatta $\mathrm{BH}$, iki izolatta ise ÇBH saptanmıştır. Mevcut çalışmaya kıyasla suş sayımızın kısıtlı, izolatlarımızın ise çoğunlukla dirençli olması BH saptamamış olmamıza neden olabilir.

Matuschek ve arkadaşları tarafından 2017 yılında yapılan yedi farklı yöntemle toplam 32 E.coli ve K.pneumoniae izolatında kolistin direncinin araştırıldığı çalışmada ${ }^{8}$ hem Sensititre hem de Micronaut kiti için TU ve KU değerleri > \%90 olarak bulunmuştur. Her 
iki ticari kitle ÇBH saptanmamış; Sensititre ile bir izolatta, Micronaut'la iki izolatta BH saptanmıştır. Araştırmacılar, kolistin duyarlıığının saptanmasında gradiyent test ve disk difüzyon yönteminin güvenilir olmadığını vurgulamışlardır.

2018 yılında Bardet ve arkadaşları tarafından yapılan birden çok yöntemin sonuçlarının kıyaslandığı geniş kapsamlı çalışmada ${ }^{15}$, Sensititre kitinin TU oranı \%96, KU oranı ise \%94.7 olarak bulunmuş; \%10.2 oranında BH saptanırken, ÇBH saptanmamıştır. Aynı çaışmada Micronaut testinin TU ve KU oranları sırasıyla \%99 ve \%90.7 olarak bulunurken, BH (\%12.8) ve ÇBH (\%5.6) kabul edilebilir değerin üzerinde saptanmıştır.

Jayol ve arkadaşlarının 185 gram negatif basilde (133 kolistin dirençli, 52 kolistin duyarlı) üç farklı yöntemi değerlendirdikleri çalışmada ${ }^{16}$ ise Sensititre sisteminin KU oranı \%97.8 olarak belirlenmiş olup; \%3 ÇBH oranı saptanırken BH saptanmamıştır.

Çalışmamızda her iki ticari yöntemle BH, ÇBH ve KU oranları (\%97-100) kabul edilebilir olmakla birlikte, TU oranı \%90'ın altında bulunmuştur. Çalışmamızdaki izolat sayısının nispeten azlığı ve suşların çoğunun dirençli olması çalışmamızın başlıca kısıtlılı̆ıdır. Değerlendirilen her iki test için de TU oranlarının düşük olması (\%74-76) bu kısıtlılığa bağlı olabilir. Çalışmamızın geliştirilmeye açık kısmı, izolatlar arasındaki klonal ilişkinin genotiplendirme yöntemleriyle araştırılmasıdır.

Sonuç olarak, çalışma kapsamında değerlendiğimiz SMD temelli her iki sistemin; kullanıma hazır olması, ek ekipman ve tecrübe gerektirmemesi, kısa sürede sonuç alınabilmesi nedeni ile kolistin duyarlıığının saptanması için rutinde kullanılabileceğini düşünmekteyiz. Daha fazla sayı ve çeşitte izolatın dahil edildiği karşılaştırmalı çalışmalarla daha güvenilir yorumlar yapılabileceği kanaatindeyiz.

\section{ETIK KURUL ONAYI}

Bu çalışma için etik kurul onayı gerekmemektedir.

\section{ÇIKAR ÇATIŞMASI}

Yazarlar bu makale ile ilgili herhangi bir çıkar çatışması bildirmemişlerdir.

\section{KAYNAKLAR}

1. World Health Organization (WHO). Global Antimicrobial Resistance Surveillance System (GLASS). The detection and reporting of colistin resistance. World Health Organization, 2018.

2. Olaitan AO, Morand S, Rolain JM. Mechanisms of polymyxin resistance: acquired and intrinsic resistance in bacteria. Front Microbiol 2014; 5: 643.

3. Simner PJ, Bergman Y, Trejo M, Roberts AA, Marayan R, Tekle T, et al. Two-site evaluation of the colistin broth disk elution test to determine colistin In Vitro activity against gram negative bacilli. J Clin Microbiol 2019; 57(2): e01163-18.

4. Chew KL, La MV, Lin RTP, Teo JWP. Colistin and polymyxin susceptibility testing for carbapenem-resistant and mcr-positive Enterobacteriaceae: Comparison of Sensititre, MicroScan, Vitek 2, and Etest with broth microdilution. J Clin Microbiol 2017; 55(9): 2609-16. 
5. Girardello R, Cury AP, Franco MRG, Di Gióia TR, de Almeida JN Jr, de Araújo MRE, et al. Colistin susceptibility testing and Vitek-2 ${ }^{\mathrm{TM}}$ : is it really useless? Diagn Microbiol Infect Dis 2018; 91(4): 309-11.

6. The European Committee on Antimicrobial Susceptibility Testing - EUCAST. MIC and zone diameter distributions and ECOFFs, V.9.0 valid from 2019-01-01.

7. ISO 20776-1:2019. Susceptibility testing of infectious agents and evaluation of performance of antimicrobial susceptibility test devices - Part 1: Brothmicrodilution reference method for testing the in vitro activity of antimicrobial agents against rapidly growing aerobic bacteria involved in infectious diseases. ISO, 2019.

8. Matuschek E, Ahman J, Webster C, Kahlmeter G. Antimicrobial susceptibility testing of colistin - evaluation of seven commercial MIC products against standard broth microdilution for Escherichia coli, Klebsiella pneumoniae, Pseudomonas aeruginosa, and Acinetobacter spp. Clin Microbiol Infect 2018; 24(8): 865-70.

9. Nordmann P, Jayol A, Poirel L. Rapid detection of polymyxin resistance in Enterobacteriaceae. Emerg Infect Dis 2016; 22(6): 1038-43.

10. Poirel L, Larpin Y, Dobias J, Stephan R, Decousser JW, Madec JY, et al . Rapid Polymyxin NP test for the detection of polymyxin resistance mediated by the $\mathrm{mcr}-1 / \mathrm{mcr}-2$ genes. Diagn Microbiol Infect Dis. 2018; 90(1): 7-10.

11. Bardet L, Okdah L, Le Page S, Baron SA, Rolain JM. Comparative evaluation of the UMIC Colistin kit to assess MIC of colistin of gram-negative rods. BMC Microbiol 2019; 19(1): 60.

12. Dafopoulou K, Zarkotou O, Dimitroulia E, Hadjichristodoulou C, Gennimata V, Pournaras S, et al. Comparative evaluation of colistin susceptibility testing methods among carbapenem-nonsusceptible Klebsiella pneumoniae and Acinetobacter baumannii clinical isolates. Antimicrob Agents Chemother 2015; 59(8): 4625-30.

13. ECDC Technical Report. Laboratory manual for carbapenem and colistin resistance detection and characterisation for the survey of carbapenem- and/or colistin-resistant Enterobacteriaceae. ECDC, 2019.

14. Pfennigwerth N, Kaminski A, Korte-Berwanger M, Pfeifer Y, Simon M, Werner G, et al. Evaluation of six commercial products for colistin susceptibility testing in Enterobacterales. Clin Microbiol Infect 2019; 25(11): 1385-9.

15. Bardet L, Rolain JM. Development of new tools to detect colistin-resistance among Enterobacteriaceae strains. Can J Infect Dis Med Microbiol 2018; 2018: 3095249.

16. Jayol A, Nordmann P, André C, Poirel L, Dubois V. Evaluation of three broth microdilution systems to determine colistin susceptibility of Gram-negative bacilli. J Antimicrob Chemother 2018; 73(5): 1272-8. 